\title{
Foreword
}

\section{The7th International Conference on Biomedical Engineering and Biotechnology}

\author{
Carlos Gómez ${ }^{\mathrm{a}, *}$ and Severin P. Schwarzacher ${ }^{\mathrm{b}}$ \\ ${ }^{a}$ Biomedical Engineering Group, University of Valladolid, Valladolid, Spain \\ ${ }^{\mathrm{b}}$ Division of Cardiology, Private Clinic Josefstadt, Confraternität, Austria
}

Welcome to this Supplement Issue of the Technology and Health Care journal, which brings together a selection of papers of the 7th International Conference on Biomedical Engineering and Biotechnology (iCBEB 2018). The aforementioned conference was held from October 17th to October 20th, 2018 in Nanjing (China), a popular travel destination with abundant historical and cultural heritages.

The topics of interest of iCBEB 2018 include medical imaging, biomedical signal processing, biomechanical engineering, molecular biology, chemistry, pharmacology and toxicology, among others. The conference would not be possible without the high quality contributions, which cover a broad range of the aforementioned topics: development of a diagnosis expert system for typhoid fever, monitoring of activities of daily living with wearable sensors, complexity analysis of the atrial dynamic system for prediction of atrial fibrillation, design of an ultrawide-angle optical system suitable for high-performance ophthalmology and dermatology applications, development of a system that transforms visual-spatial information into auditory information, design of an interoperable framework based on blockchain for electronic health record sharing, etc.

We would like to express our gratitude to the Publisher and Editor-in-Chief of the Technology and Health Care journal for the publication of this Supplement Issue. We also wish to acknowledge the members of the Technical Program Committee, headed by Prof. Eddie Ng Yin Kwee, and of the Local Committee from Southeast University and Nanjing Medical University for their support.

Finally, we hope to meet you in Seoul (Republic of Korea) at the 8th International Conference on Biomedical Engineering and Biotechnology (iCBEB 2019), hosted by Institute of Bio-medical Engineering Research, Kyungpook National University and supported by Center for the Support of Medical Device Platform, Keimyung University.

\footnotetext{
${ }^{*}$ Corresponding author: Carlos Gómez, University of Valladolid, E.T.S.I. Telecomunicación, Paseo de Belén, 15, 47011Valladolid, Spain. E-mail: carlos.gomez@tel.uva.es.
}

0928-7329/19/\$35.00 (c) 2019 - IOS Press and the authors. All rights reserved

This article is published online with Open Access and distributed under the terms of the Creative Commons Attribution NonCommercial License (CC BY-NC 4.0). 